\title{
Recognizing the Centrality of Cultural Diversity and Racial Equity: Beginning a Discussion and Critical Reflection on Developmentally Appropriate Practice
}

Judith K. Bernhard

Ryerson University

Janet Gonzalez-Mena

Napa Valley College

Hedy Nai-Lin Chang

California Tomorrow

\section{Michael O'Loughlin}

Hofstra University

Costanza Eggers-Pierola

Wheelock College

digital.library.ryerson.ca/object/3

\section{Please Cite:}

Bernhard, J. K., Gonzalez-Mena, J., Chang, H. N., O'Loughlin, M, EggersPierola, C., Roberts Fiati, G., \& Corson, P. (1998). Recognizing the centrality of cultural diversity and racial equity: Beginning a discussion and critical reflection on developmentally appropriate practice. Canadian Journal of Research in Early Childhood Education, 7(1), 81-90.

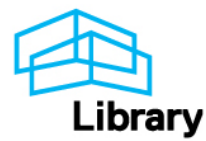




\title{
Recognizing the centrality of cultural diversity and racial equity: Beginning a discussion and critical reflection on Developmentally Appropriate Practice
}

\author{
Judith K. Bernhard \\ Ryerson Polytechnic University \\ Janet Gonzalez-Mena \\ Napa Valley College, US \\ Hedy Nai-Lin Chang \\ California Tomorrow, US \\ Michael O'Loughlin \\ Hofstra University \\ Costanza Eggers-Piérola \\ Wheelock College \\ Gloria Roberts Fiati and Patricia Corson \\ Ryerson Polytechnic University
}

Child care standards in both the United States and Canada are in large measure based upon those set out in the document of the National Association for the Education of Young Children (NAEYC) entitled Developmentally Appropriate Practice in early childhood education programs (DAP; Bredekamp \& Copple, 1997). This document is intended for "administrators, teachers, parents, policy makers, and others who make decisions about the care and education of young children" (p. 3). The principles of DAP and their alleged knowledge base shape the ways child care is delivered in North America in broad areas from legislation to teacher training to teacher-child interaction. The revised edition of this document (1997) is motivated, in part, by a recognition of the increasing cultural, racial, and linguistic diversity in the child and family population. The previous edition (Bredekamp, 1987) had discussed cultural context as part of individual differences but did not focus on the effects of context.

\footnotetext{
Acknowledgments. This manuscript was written while the first author was working under the support of a research grant from the Social Science and Humanities Research Council of Canada. An earlier version of this paper was presented at the 1998 Reconceptualizing Early Childhood Education conference in Honolulu. We thank Ryerson Polytechnic University for providing this travel grant and the conference participants for their valuable feedback. We wish to acknowledge the helpful suggestions of three anonymous reviewers and our colleagues Harold White, Intisar Shareef. Sally Lubeck, June Pollard, and David Corson. We also appreciate the willingness of Sue Bredekamp and Carol Brunson Phillips to discuss our reaction to the revised $D A P$.

Correspondence should be addressed to :

Judith K. Bernhard, School of Early Childhood Education, Ryerson Polytechnic University, 350 Victoria St., Toronto, Ontario, Canada, M5B 2K3. Electronic mail may be sent via internet to [jbernhar@acs.ryerson.ca].
} 
We applaud Bredekamp and Copple for addressing issues of cultural and linguistic diversity directly in the 1997 edition and welcome the effort that has been made to soften the term and concept of "age-appropriate" by using less dogmatic labels such as "typical development" (e.g., p. 9, 10), and "widely held expectations [for various ages]" (e.g., p. 108). Nevertheless, we are seriously concerned that DAP is still based on the premise of universal notions of human development. Thus the introduction of ethnic, cultural, and linguistic diversity as a separate component within a model that privileges universal assumptions, marginalizes issues that we view as central to an inclusive and respectful approach to the care and education of children of diverse backgrounds.

In view of increasing diversity in countries such as Canada and the United States, the question of how to take culture properly into account is especially critical. The purpose of this article is to engage and stimulate debate on how the early childhood education system can best provide quality care for children of all backgrounds. We hope to see further revisions of DAP that fully recognize the implications of cultural and linguistic diversity and racial equity for the care and education of young children in Canada and the United States. Our concern is that unless ethnic and class diversity, poverty, and immigrant status are explicitly named and acted upon, gaps will continue to widen between the "haves" and the "have nots" in affluent societies such as the United States and Canada.

We are a group of professionals in the field who come from different racial, cultural, and linguistic backgrounds; having discussed these issues amongst ourselves, we want to invite others to join the dialogue. Many of our concerns involve what we view to be missing from the document but absences cannot be cited by page. Further, issues such as culture are discussed at many points and we cannot comment on each instance. However, we will indicate some of the main pages in which issues are discussed so the reader can inspect these in context and form an opinion on the issues. Our comments will fall into five categories: (1) culture and universality, (2) parent-professional partnerships; (3) language issues and bilingualism; (4) anti-bias education; and (5) the explanation of school failure for certain groups.

\section{Culture and universality}

Rather than recognizing the inherently socioculturally situated nature of child development, the authors of DAP treat it simply as another source of variation, just like individual differences.

Developmentally appropriate practices result from the process of professionals making decisions about the well-being and education of children based on at least three important kinds of information: 1) what is known about child development and learning - knowledge of agerelated human characteristics that permits general predictions within an age-range about what materials, activities, interactions, or experiences will be safe, healthy, interesting, achievable, and also challenging to children; 2) what is known about the strengths, interests, and needs of each individual child in the group to be able to adapt to and be responsive to inevitable individual variations; and 3) knowledge of the social and cultural context in which children live and develop to ensure that learning experiences are meaningful, relevant, and respectful for the participating children and their families. (underlining added; Bredekamp \& Copple, 1997, pp. 8-9)

Although the above approach is an important step forward, we believe that it remains problematic. It encourages practitioners to consider the possible impact of culture while leaving intact the assumption that the current childdevelopment knowledge base generally holds true for all children ("permits general predictions within an age-range"). In order to prepare practitioners to provide quality child care to increasingly diverse children and families, we believe that DAP must recognize the foundational and defining role of cultural context: the alleged "general predictions", in fact, are rooted in the particular, dominant culture. Therefore it 
is a conceptual mistake to treat cultural context as an influence on an alleged universal pattern, and this mistake has harmful consequences.

The fundamental issue at stake here is a matter of world-view. Practitioners and theorists who draw on a Piagetian tradition value individual experience, and view development as a trajectory toward increased rationality and autonomy (Bernhard, 1995; O'Loughlin, 1992; Walkerdine, 1984). Those drawing upon the theories of Vygotsky and Bakhtin have tended to look toward the sociohistorical and sociocultural focus of development (O'Loughlin, 1995, in preparation; Wertsch, 1991). Furthermore, those influenced by Vygotsky's concept of a zone of proximal development (Vygotsky, 1962, 1978) argue for the kind of assisted or scaffolded growth that is at variance with a model based on personal autonomy. We recognize attempts to include Vygotskian perspectives (e.g., pp. 12-14), but we argue that these are essentially add-ons to an age/stage universalistic approach.

For the most part, the field has been based upon a knowledge of how child development occurs for a limited sample of the children in the world - namely European American, white, middle-class children. Reviews of child development journals conducted in the 1970s and late 1980s indicate that less than 10 percent of studies involved non-white children (LeVine, 1980; New, 1992) and there is much evidence to indicate systematic racial bias in psychology (Morawski, 1997; O'Loughlin, 1997a, 1997b). Although there is recognition of dominant and majority culture in the DAP document (e.g., Bredekamp \& Copple at pp. 33-34, 37, 118-119) and an attempt to honor cultural variance (e.g., Bredekamp \& Copple at pp. $6,12,18,20$ ), the authors of DAP need to go further and drop implicit notions of universality as in sections entitled "Widely Held Expectations" or "Developmental Milestones". In fact, development cannot be defined apart from culture.

The lack of attention to the foundational and defining role of culture is particularly evident in some of the alleged instances of appropriate versus inappropriate behavior for each age group. Four examples of this follow:

(1) There is the statement that "being physically close can thwart a mobile infant's urge to explore" (Bredekamp \& Copple, 1997, p. 56).

(2) Bredekamp and Copple emphasize the value of solitary play far more than other cultures:

\section{Appropriate Practices Inappropriate Practices Adults respect toddlers' Adults do not understand solitary and parallel play the value of solitary play and try to force children to play together (p. 84).}

By contrast, we propose that different cultural groups have different assumptions about how much independence versus interdependence issues should be emphasized, and their differing values become manifest in their child-rearing practice. For example, the extremely high value placed on independence by the dominant culture of the United States and Canada, results in child development practices that emphasize infants learning to eat by themselves and exploring the world around them with minimal levels of direction from the adults in their environment.

(3) Another example of cultural narrowness concerns the toddler's responsibility for eating, toileting and dressing (p. 85).

(4) There is the authors' assertion that it is "inappropriate practice" when "teachers do things for [35 year-old] children that they could do for themselves because it is faster and less messy" (p. 126).

We disagree because we know of many parents who do not give toddlers any large responsibility for selfhelp in eating, toileting, and dressing and we do not assume that their actions hinder development as they see it. Their priorities are relationships and interdependence, more than autonomy. Their notions of autonomy and development are rooted in their culture and their goals for children are genuinely 
different than those of the (so-called) North American mainstream.

While the document asserts that culture influences what is viewed as typical development (pp. 12, 4143), we invite the reader to consider the fundamental difference between an additive approach and a socioculturally situated approach - the latter acknowledges that children are fully culturally constituted beings, and the pedagogical/caretaking task is to affirm and embrace children in their diverse ways of being. Chamoiseau's (1997) writing about Martinique aptly characterized how it feels for children to shed their culture and become molded into universal norms:

We went to school to shed bad manners: rowdy manners, nigger manner, Creole manners - all the same thing... The vibrant spirit of learning and our Creole beings seemed to be in insurmountable contradiction. The teacher had not only us to contend with but also the entire country. He saw himself embarked upon as a mission of civilization, something like those missionaries who bury themselves in savage lands. Day after day, from one watering hole to another, without an ounce of pleasure, these finders of lost souls pressed on. The effort demanded was colossal, beyond mere brute strength. Since he had to slog through the mire every second he spent with us, each of his gestures, commands, and murmurs was armored with the Universal. The Universal was a buckler, a disinfectant, a religion, a hope... . (pp. 120-1)

\section{Parent-professional partnerships}

Although Bredekamp and Copple are to be commended for advocating reciprocal relationships between teachers and parents and for the empowerment of parents (p. 22, 64), the recommendation sounds hollow in view of the virtual silence of DAP regarding the inequities in power relations that often prevent parents from being treated as equal partners. Successful collaboration by parents has been found to depend on social class and ethnicity and agreement with the school's approach and academic agenda; lack of success is imputed when parents are not perceived to share the approach of the school (Bemhard, Freire, \& Pacini, 1998; Brantingler, 1985; Lareau, 1989; O'Louglin, 1997b). The work of Delgado Gaitan (1990), Walshe (1996), and Valdes (1996) demonstrates the complexity of interactions between Latino families and school, and Anyon (1997) and Quint (1994) have demonstrated the complexity of these interactions for marginal urban children, including homeless populations.

While the document endorses the goal of parental involvement, it should go further than making recommendations to consult with parents. Providers should be aware that some parents may have opinions but not feel that they are in a position to make them known perhaps because of discrimination, cultural differences in views toward teachers, or even the fact that they are low income wage earners. Some parents do not want to criticize a teacher because of their fear that it will cause them to lose their valuable subsidized child care space or have possible repercussions for their child. Parents from minority groups may not feel a sense of power. These issues are not adequately considered, and we believe DAP should urge caregivers to take an active role in soliciting information from parents. It would be useful for the authors of DAP to provide examples of programs that promote collaboration with parents. The field of ECE has a rich history of such programs, ranging from parent co-ops to Head Start. In sum, DAP should go beyond endorsing equal partnerships and propose ways in which the pre-requisites of such reciprocal relationships can be established.

\section{Language issues and bilingualism}

Language issues and bilingualism are matters of increasing importance for both the United States and Canada. In both countries, more children than ever before come from homes where languages other than English are spoken. This linguistic diversity is a significant asset because it can offer children, both those 
who speak English and those who are speakers of other languages, opportunities to become bilingual or multilingual. Bilingualism promotes cognitive flexibility and increases employability in an increasingly global economy. At the same time, maintenance of the mother tongue is critical to children remaining connected to family, community, and their cultural background.

The document mentions that children "should be able to learn English without being forced to give up their home language"; that learning English can be "an additive process" (p. 13). Likewise, the recommendation to bring a child's home language and culture into the school is an important step (pp. 9, 18). But the DAP document does not pay enough attention to the subtle ways in which the use of the home language is undermined by the dominant language of the school. The issues of actively encouraging parents to maintain the home language need to be addressed; to say that we should not have children "being forced to give up their home language" simply does not go far enough. A great many studies show that learning the second language in an additive way is the exception, rather than the rule (e.g., Cummins, 1996; Wong Fillmore, 1990). Losing the home language, we propose, is generally the outcome if there are no active measures of support from the teacher. As Chamoiseau's (1997) devastating tale of his experiences as a Creole speaker in the Fran-cophone schools of Martinique so powerfully illus-trates, subtractivity erases a child's ethnic and cultural identity, and hence can do irreparable damage to his or her self-esteem.

The role of schools in supporting bilingualism and preserving home languages also needs to be addressed. Similar arguments can be made in relation to nondominant forms of English, such as African American English, as Delpit and Perry (1997) illustrate.

One obvious and helpful approach to home language maintenance is the use of staff with bilingual, bicultural backgrounds who have been sensitized to value and nurture ethnic and linguistic differences. There are no references included in DAP regarding the hiring of staff who speak the children's home language. Yet there is evidence that lack of such staff is a major problem in the field (Bernhard, Lefebvre, Chud, \& Lange, 1996; Chang, 1993; LaGrange, Clark, \& Munroe, 1994). Likewise, there is no mention of grouping children so that they have a chance to be with other children who speak the same language. Validating and maintaining one's home language constitutes a form of empowerment. There is a wealth of information in the position paper already developed by NAEYC (1995; See also special issue Volume 5, Number 2 of this journal).

In sum, we believe the DAP document needs to affirm equitable treatment for all languages and specifically propose a goal of bilingualism and biculturalism for all children. Specific measures should be outlined to support parents and encourage the home language both in the home and in the school.

\section{Anti-bias education}

The DAP document pays insufficient attention to bias, how it emerges, and how it may be addressed in the classroom (e.g., pp. 4, 7). There is mention of the importance of having pictures of people from different backgrounds (e.g., p. 87), but it does not offer examples of how teachers can intervene when they hear children making prejudicial statements about others and also saying things about themselves like "I am not as pretty because I' $m$ too dark." The DAP does not discuss the fact that minority children's self-esteem may be damaged through discrimination; we propose that the document spell out clearly that teachers should make great efforts to help the children gain self esteem and value their culture.

Teachers need more understanding of the formation of racial identity, and they should have explored their own racial identity formation in ways that allow them to be comfortable enough raising these issues with children and families. The DAP document, however, does not mention the importance of having providers who reflect the children's racial backgrounds and therefore can provide successful role models of people who look like them. 
We note that DAP and the Anti-Bias Curriculum (Derman-Sparks, 1989) are two of the best selling documents of NAEYC, and yet DAP does not reflect many of the fundamental issues affecting children's development and education, raised in the Anti-Bias Curriculum. In sum, we believe DAP should go much further in pointing out that teachers of young children can play a critical role in helping to combat personal prejudice, institutional bias, and the impact of internalized oppression.

\section{The Explanation of School Failure for Certain Groups}

The document addresses the fact that children need more than they are getting in the primary grades. "As with preschool and child care, the observed quality of children's early schooling is uneven... Currently, too many children, especially those from low-income families and some minority groups, experience school failure, are retained in grade, get assigned to special education, and eventually drop out of school" (Bredekamp \& Copple 1997, p. 7). The document recognizes a serious problem, but where does it place the responsibility? The implication is that the problem stems from a lack of developmentally appropriate practice in classrooms (p. 20). This explanation ignores more basic causes such as values, stereotypes and expectations. The primary factor of low achievement is undoubtedly poverty (Anyon, 1997; Gans 1995; Wilson, 1987). Structural inequities and infrastracture deficiencies must be addressed, espe-cially the complex interaction of different sociological variables on individual children. Race, class, gender and ethnicity combine to affect different groups of children in different ways (D. Corson, 1998). In both Canada and the United States, there is a lack of pedagogy that touches the life experiences of children (P. Corson, 1998; Goddard, 1995; Orlikow \& Young, 1993. For the United States situation, see Olsen \& Mullen, 1990 , 1994).

Other factors contributing to the problem are inequitable school financing, which results in illequipped and over-crowded inner city schools badly in need of repair. (Kozol, 1991). Tracking is another factor (Oakes, 1985; Mehan, 1997). When professionals' attitudes and expectations are influenced by racism, classism, and commonly used criteria of standard English proficiency, children find themselves in low level classes with a watered-down curriculum and they are set up for failure.

It will be said that social ills have no proper place in an account of child development. We would argue, to the contrary, that the schools, as places of primary contact with children and families, should not narrowly confine themselves to dealing only with education issues. Besides the child's social and educational processes in the school, his or her general security, safety, and health are all relevant. We think it is unfortunate that DAP limited its scope to considering what happens in classrooms and schools. We agree with McLoyd (1990), that one cannot see poverty as simply an outside variable; rather it is a feature of the ecological setting of what are usually described as parental characteristics, which directly affect child development.

If failure is explained by individual traits or by parental practices in a vacuum, there is a danger of ignoring obvious ecological factors. McLoyd (1990) cites studies that show that poverty and class have a causal role in parental distress and, therefore, a direct impact on academic and social developmental variables. Similarly, cultural traits (e.g., expectations attributed to cultural groups) are also mediated by personal distress and reflect the economic hardship and conditions, and this relates directly to the child's development. Without considering these factors as integral, one runs the risk of blaming parents and proposing ineffective solutions.

The answer the authors of DAP propose is "a shared vision and agreed-upon standards of professional practice" (p. 7) and do not recognize the cultural specificity of goals such as toddler autonomy. In contrast, our non-universalistic approach was precisely stated by Garcia Coll et al. (1996).

According to organizational models, develop- 
ment in children of color cannot be judged solely in relation to a specific 'standard norm' applied to all children, but must be considered within the context of specific ecological circumstances. (p. 1907)

If, as we argued above, the existence of any typical or universal patterns is entirely questionable, the issue becomes one of on-going multiple definitions of good practice embedded in a diversity of cultures. Such definitions can be formed only within the various communities and cultures, and provide a foundation for "shared vision and agreed-upon standards of professional practice". Each community should identify appropriate and inappropriate practices based on the unique and different goals of families and cultural groups, and professionals have an important, collaborative part to play.

\section{Proposals and conclusion}

There is a need for more research and greater awareness of existing research that furthers our understanding of diverse developmental patterns and practices based in various cultural contexts (e.g., Bernhard \& Freire, 1996; Chang, Muckelroy, \& Pulido-Tobiasen, 1996; D. Corson, 1998; Gonzalez-Mena, 1997; Greenfield \& Cocking, 1994; Harkness, Super, Keefer, Raghavn, \& Campbell, 1996; Kagitçibasi, 1996; Lubeck, 1994; McLoyd \& Spencer, 1990; Walsh, 1991). Besides international ECE research dealing with cultures in other countries, one needs to understand their transplantation and juxtaposition in North America. For someone from one culture to truly understand the perspective of someone from another culture, she / he must have access to a diverse body of research (Hall, 1997; McAdoo, 1993; Nakanishi \& HiranoNakanishi, 1993; Weinberg, 1997). As to practical application, we propose careful examination of the internships and placements students have in relation to cultural and racial diversity (Bernhard, Lefebvre, Kilbride, Chud, \& Lange, 1998; O'Loughlin, in press).

In closing, the question we wish to pose is: How much does the revised DAP document represent a perpetuation of the status quo? Would its application in Canada and the United States provide adequate guidance to address the current complexities of language and culture? We have argued that the document is insufficient as would be the practice derived from it. This does not deny that present DAP-based practice represents an improvement over previous standards. DAP, in its virtual silence on poverty and racism, can be interpreted as maintaining that power inequities in our society are irrelevant to the development of young children. Theorizing within the field of ECE must undergo radical change. We call for the DAP authors to make a clear statement that optimal child development does not occur in situations of social injustice. The goal is for all citizens of Canada and the United States to have equitable social arrangements allowing for full development of all human beings from all racial, cultural, linguistic, and class backgrounds, particularly women and children.

\section{REFERENCES}

Anyon, J. (1997). Ghetto schooling: A political economy of urban educational reform. NY: Teachers College Press.

Bernhard, J. K. (1995). The changing field of child development: Cultural diversity and the professional training of early childhood educators. Canadian Journal of Education, 20, 415-436.

Bernhard, J. K. (1998). Latin American, Asian and African children in the Canadian educational system: The issue of linguistic and cultural match. American Educational Research Association annual meeting, San Diego, April.

Bernhard, J. K., \& Freire, M. (1996). Latino refugee children in child care: A study of parents and caregivers. Canadian Journal of Research in Early Childhood Education, 5, 59-71.

Bernhard, J. K., Freire, M., \& Pacini, V. (1998). Resisting enculturation in Canadian elementary schools: Culturally contested issues of Latin American Parents. Nineteenth Annual Ethnography in Education Research Forum, Philadelphia, PA.

Bernhard, J. K., Lefebvre, M. L., Chud, G., \& 
Lange, R. (1996). Linguistic match between children and caregivers in Canadian early childhood education. Canadian Journal of Research in Early Childhood Education, 5, 5-18.

Bernhard, J. K., Lefebvre, M. L., Kilbride, K. M., Chud, G., \& Lange, R. (1998). Troubled relationships in early childhood education: Parent-teacher interactions in ethnoculturally diverse settings. Early Education and Development, 9 (1), 5-28.

Brantlinger, E. (1985). Low-income parents perceptions of favoritism in the schools. Urban Education, 20, 82-102.

Bredekamp, S. (1987). Developmentally appropriate practice in early childhood programs serving children from birth through age eight. Washington, DC: National Association for the Education of Young Children (NAEYC).

Bredekamp, S., \& Copple, C. (Eds.). (1997). Developmentally appropriate practice in early childhood programs. Washington, DC: National Association for the Education of Young Children (NAEYC).

Chamoiseau, P. (1997). School days. Lincoln: University of Nebraska Press.

Chang, H. (1993). Affirming children's roots: Cultural and linguistic diversity in early care and education. San Francisco, CA: California Tomorrow.

Chang, H., Muckelroy, A., \& Pulido - Tobiassen, D. (1996). Looking in, looking out: Redefining child care and early education in a diverse society. San Francisco, CA: California Tomorrow.

Corson, D. (1998). Changing education for diversity. Philadelphia, PA: Open University Press.

Corson, P. (1998). Anti-bias education and early childhood: Preparing teachers for diversity. University of Toronto: Unpublished doctoral dissertation.

Cummins, J. (1996). Negotiating identities: Education for empowerment in a diverse society. LA, CA: California Association for Bilingual Education.

Delgado-Gaitan, C. (1990). Literacy for empowerment: The role of parents in children's education. NY: Falmer Press.

Delpit, L., \& Perry, T. (Eds.). (1997). The real ebonics debate: Power, language, and the education of African-American children. Special issue of Rethinking Schools, 12 (1), Fall.
Derman-Sparks, L., \& the ABC Task Force (1989). Anti-bias curriculum: Tools for empowering young children. Washington, DC: National Association for the Education of Young Children.

Gans, H. (1995). The war against the poor. NY: Basic Books.

Garcia Coll, C., Lamberty, G., Jenkins, R., Pipes McAdoo, H., Crnic, K., Wasik, B., \& Vazquez Garcia. (1996). An integrative model for the study of developmental competencies in minority children. Child Development, 67, 1891- 1914.

Goddard, J. T. (1995). The ethnocultural preparation of teachers. Paper presented at the annual conference of the American Educational Research Association, San Francisco, CA.

Gonzalez-Mena, J. (1997). Multicultural issues in child care. Mountain View, CA: Mayfield.

Greenfield, P. M., \& Cocking, R. R. (Eds.). (1994). Cross-cultural roots of minority child development. Hillsdale, NJ: Lawrence Erlbaum.

Hall, P. M. (Ed.). (1997). Race, ethnicity, and multiculturalism: Policy and practice. NY: Garland Press.

Harkness, S., Super, C. M., Keefer, C. H., Raghavn, C. S., \& Campbell, E. K. (1996). Ask the doctor: The negotiation of cultural models in American parentpediatrician discourse. In S. Harkness and C. M. Super (Eds.), Parental cultural belief systems: Their origins, expressions, and consequences (pp. 289-310). NY: Guilford Press.

Kagitçibasi, C. (1996). Family and human development across cultures: A view from the other side. Hillsdale, N.J.: Lawrence Erlbaum.

Kozol, J. (1991) Savage inequalities: Children in America's schools. NY: Crown Publishers.

LaGrange, A., Clark, D., \& Munroe, E. (1994). Culturally sensitive child care: The Alberta study. Calgary: Alberta Citizenship and Heritage Secretariat. Lareau, A. (1989). Home advantage: Social class and parental intervention in elementary education. Philadelphia, PA: Falmer Press.

Levine, R. A. (1980). Anthropology and child development. New Directions for Child Development, 8, 71-86.

Lubeck, S. (1994). Children in relation: 
Rethinking early childhood education. Urban Review, 26 (3), 153-172.

McAdoo, M. P. (1993). Family ethnicity. Newbury Park, CA: Sage.

McLoyd, V. (1990). The impact of economic hardship on black families and children: Psychological distress, parenting, and socioemotional development. Child Development, 61, 311-346.

McLoyd, V., \& Spencer, M. B. (Eds.). (1990). Special issue on minority children. Child Development, $61(2)$.

Mehan, H. (1997). Tracking untracking: The consequences of placing low-track students in hightrack classes. In P. Hall (Ed.), Race, ethnicity, and multiculturalism: Policy and practice. NY: Garland Press.

Morawski, J. M. (1997). White experimenters, white blood, and other white conditions: Locating the psychologist's race. In M. Fine, L. Weis, L. C. Powell, \& L. M. Wong (Eds.), Off white: Readings on race, power and society. NY: Routledge.

Nakanishi, D., \& Hirano-Nakanishi, M. (Eds.). (1993). The education of Asian and Pacific Americans: Historical perspectives and prescriptions for the future. Phoenix: Oryx Press.

National Association for the Education of Young Children (1995). NAEYC position statement. Responding to linguistic and cultural diversity: Recommendations for effective early childhood education. Young Children, 4-16.

New, R. (1992). Babies and bathwater: Uses and abuses of child development research and developmentally appropriate practice. Paper presented at the American Educational Research Association, San Francisco, CA, April.

Oakes, J. (1985). Keeping track: How schools structure inequality. New Haven: Yale University Press.

O'Loughlin, M. (1992). Rethinking science education: Beyond Piagetian constructivism toward a sociocultural model of teaching and learning. Journal of Research in Science Teaching, 29, 791-820.

O'Loughlin, M. (1995). Six propositions concerning children, their worlds, and the words we use to describe them. Paper presented at the Reconcep- tualizing Research in Early Childhood Education conference, Santa Rosa, CA.

O'Loughlin, M. (1997a). Imagining a socially just and racially inclusive psychology: Musings from postcolonial theory. Paper presented at the Fifth European Congress of Psychology, University College Dublin, Dublin, Ireland.

O'Loughlin, M. (1997b). Helping poor and working class children make something of themselves: The contradictions and possibilities of teaching for equity and democracy. Democracy in Education, 12 (1), 3033.

O'Loughlin, M. (in preparation). Seven principles underlying socially just and ethnically inclusive teacher preparation.

Olsen, L., \& Mullen, N. (1990). The unfinished journey: Restructuring schools in a diverse society. San Francisco, CA: California Tomorrow.

Olsen, L., \& Mullen, N. (1994). Embracing diversity. San Francisco, CA: California Tomorrow.

Orlikow, L., \& Young, J. (1993). The struggle for change: Teacher education in Canada. In G. K. Verma, (Ed.), Inequality and teacher education. London: Falmer Press.

Philips, S. U. (1993). The invisible culture: Communication in classroom and community on the Warm Springs Indian Reservation. Prospect Heights, IL: Waveland Press.

Troyna, B., \& Hatcher, R. (1992). Racism in children's lives: A study of mainly-white primary schools. London: Routledge.

Valdes, G., (1996). Con respeto: Bridging the distance between culturally diverse families and schools. NY: Teachers College Press.

Vygotsky, L. S. (1962). Thought and language. Cambridge, MA: MIT Press.

Vygotsky, L. S. (1978). Mind in society: The development of higher psychological processes. Cambridge, MA: Harvard University Press.

Walkerdine, V. (1984). Developmental psychology and the child-centered pedagogy: The insertion of Piaget's theory into primary school practice. In J. Henriques et al. (Eds.), Changing the subject: Psychology, social regulation and subjectivity. London: Methuen. 
Walsh, D. J. (1989). Changes in kindergarten: Why here? Why now? Early Childhood Research Quarterly, 4, 377-391.

Walshe, C. (Ed.). (1996). Education reform and social change: Multicultural voices, struggles, visions. Mahwah, NJ: Erlbaum.

Wertsch, J. (1991). Voices of the mind. A sociocultural approach to mediated action. Cambridge, MA: Harvard University Press.

Wilson, W. J. (1987). The truly disadvantaged: The inner city, the underclass, and public policy. Chicago: University of Chicago Press.

Weinberg, M. (Ed.). (1997). Asian-American education: Historical background and current realities. Mahwah, NJ: Erlbaum.

Wong Fillmore, L. (1991). When learning a second language means losing the first. Early Childhood Research Quarterly, 6, 323-346.

Young-Bruehel, E. (1996). The anatomy of prejudice. Boston, MA: Harvard University Press. 